\title{
PREDICTIVE VALUE OF ULTRASONOGRAPHY \& COMPUTED TOMOGRAPHY IN CIRRHOTIC PATIENTS OF ALL AETIOLOGIES TO EVALUATE FOCAL LESIONS IN LIVER \& OUTCOME
}

\author{
Shani J. ${ }^{1}$, Vinoo Jacob², V. L. Retnakumari3 ${ }^{3}$, K. T. Shenoy 4
}

${ }_{1}^{1}$ Assistant Professor, Department of Radio Diagnosis, Sree Gokulam Medical College and Research Foundation, Venjaramoodu, Kerala, India.

2Professor, Department of Radio Diagnosis, Sree Gokulam Medical College and Research Foundation, Venjaramoodu, Kerala, India. 3Professor and HOD, Department of Radio-diagnosis, Sree Gokulam Medical College and Research Foundation, Venjaramoodu, Kerala, India.

${ }^{4}$ Professor, Department of Gastroenterology, Sree Gokulam Medical College and Research Foundation, Venjaramoodu, Kerala, India.

ABSTRACT
BACKGROUND
Incidence of focal lesions in liver- hepatocellular carcinoma (HCC), benign regenerating nodules, secondaries etc., are expected to
increase largely due to hepatitis C infection and secondary cirrhosis. HCC is being detected at an earlier stage owing to the
implementation of screening programs. Biopsy is no longer required prior to treatment, and diagnosis of HCC is heavily dependent
on imaging characteristics. We wanted to detect and follow all hepatic focal lesions in CLD by USG \& CT. We also wanted to assess
the sensitivity \& specificity, PPV and NPV by USG \& CECT for identifying benign and malignant lesions.

\section{METHODS}

This prospective study, (diagnostic evaluation) was conducted in Sree Gokulam Medical College \& Research Foundation, Venjaramoodu, Trivandrum. Study population included all clinically diagnosed cases of CLD, who were referred to Department of Radiology for USG and CECT. These patients were followed up for 18 months (November 2012-June 2014). Data was compiled and analysed using statistical package- SPSS Version 17.0. All cirrhotic patients were diagnosed by clinical, biochemical \& imaging techniques and if a focal liver lesion is incidentally detected in a routine USG abdomen in a cirrhotic patient, they were included in the study. Very sick patients with hepatic failure and patients who did not give consent for follow up \& participation in the study were excluded from the study.

\section{RESULTS}

Among 121 cirrhotic patients, the sensitivity of ultrasonography in detecting malignancy as hypoechogenecity of lesions or extension of lesion to adjacent structures was $100 \%$ \& those with both hypoechogenecity of lesions and extension of lesion to adjacent structures was only $48.4 \%$. The sensitivity of CECT in detecting malignancy was $97.5 \%$. The specificity of ultrasonography in detecting malignancy as hypoechogenecity of lesions or extension of lesion to adjacent structures was $16.7 \%$ \& those with both hypoechogenecity of lesions and extension of lesion to adjacent structures was $100 \%$. The specificity of CECT in detecting malignancy was $83.3 \%$

\section{CONCLUSIONS}

Hence USG is a screening diagnostic modality \& CECT is an accurate diagnostic tool for evaluating benign from malignant focal lesions in liver, and invasive modalities like liver biopsy could be prevented by proper \& planned dynamic contrast study of abdomen.

\section{KEY WORDS}

CLD: Chronic Liver Disease, USG: Ultrasonography, CT: Computed tomography, CECT: Contrast Enhanced Computed Tomography, PPV: Positive Predictive Value, NPV: Negative Predictive Value

HOW TO CITE THIS ARTICLE: Shani J, Jacob V, Retnakumari VL, et al. Predictive value of ultrasonography \& computed tomography in cirrhotic patients of all aetiologies to evaluate focal lesions in liver \& outcome. J. Evolution Med. Dent. Sci. 2019;8(28):2274-2278, DOI: $10.14260 /$ jemds/2019/498

\section{BACKGROUND}

Incidence of focal lesions in liver- hepatocellular carcinoma (HCC), benign hepatic lesions like haemangioma, adenoma, fibronodular hyperplasia, regenerating nodules, metastasis to liver are expected to increase largely due to hepatitis $\mathrm{C}$ infection and secondary cirrhosis.

'Financial or Other Competing Interest': None.

Submission 18-06-2015, Peer Review 27-06-2019,

Acceptance 05-07-2019, Published 15-07-2019.

Corresponding Author:

Dr. Shani J,

Shanu Manzil, Alissery Ward,

Alappuzha, Kerala, India.

E-mail: drshani1985@gmail.com

DOI: $10.14260 /$ jemds $/ 2019 / 498$

\section{(c) (i) $($ )}

HCC is the most common tumour being detected at an earlier stage owing to the implementation of screening programs in the background of chronic liver disease as alcoholism and hepatitis $\mathrm{B}$ and $\mathrm{C}$ infections. Biopsy is no longer required prior to treatment, and diagnosis of HCC is heavily dependent on non-invasive imaging modalities with the aid of screening ultrasonography and problem-solving tool as contrast enhanced computed tomography. The most recent recommendations by the American Association for the Study of Liver Diseases (AASLD) state that a diagnosis of HCC can be made if a mass larger than $2 \mathrm{~cm}$ shows typical features of HCCHypoechoic lesions in ultrasound \& (Hypervascularity in the arterial phase and washout in the venous phase) at contrast material-enhanced computed tomography shows these features at both modalities(1) (Fig- 1a \&1b). 
The role of fine-needle aspiration biopsy (FNA) in the diagnosis of hepatocellular nodular lesions $(<2 \mathrm{~cm})$ is very challenging \& has evolved over the years. Accurate tissue characterization of small well-differentiated hepatocellular nodular lesions $(<2 \mathrm{~cm})$ is very challenging and has significant therapeutic implications. $(2,3)$ The focus is on hepatocellular nodular lesions associated with cirrhosis. In this back ground this study has been carried out to evaluate for focal lesions in liver in cirrhotic by using imaging modalities.

\section{Aims and Objectives}

1. To follow up chronic liver diseases and identify focal lesions in liver by USG \& CT.

2. To assess the sensitivity \& specificity, positive predictive value \& negative predictive value by USG \& CECT for identifying benign \& malignant lesions.

\section{METHODS}

The study was conducted in the department of Radiodiagnosis of Sree Gokulam Medical College \&Research Foundation. All clinically diagnosed cases of I CLD patients of all aetiologies was evaluated with initial screening modality of USG. The study was conducted from September 2012 till September 2015. The study was designed as a Prospective study, Diagnostic evaluation. Informed written consent was taken from all patients and IEC clearance was taken and study was approved.

\section{Inclusion Criteria}

1. All clinically diagnosed cases of cirrhosis who have been referred to Department of Radiology for USG \& CECT

2. If a focal liver lesion is incidentally detected in a routine USG abdomen in a cirrhotic patient.

3. All patients of cirrhosis shall be followed up for at least 18 months.

\section{Exclusion Criteria}

Very sick patients with hepatic failure.

\section{Statistical Analysis}

Data was compiled and analysed using the statistical packageSPSS Version 17.0. It was a prospective study and diagnostic evaluation.

\section{Investigations \& Interventions}

All cirrhotic patients will be evaluated by using USG, CT and Viral markers those with suspicious focal lesions will be evaluated by further work up with gold standard investigation such as liver biopsy. Those with no focal lesion, will be followed up every 6 months for a period of 18 months and all detectable focal lesions will be subjected to CECT, AFP \& Doppler studies for portal/ IVC thrombus. All focal lesions shall be classified as benign, regenerating nodules or malignant.

All focal lesions shall be classified as benign, regenerating nodules or malignant by FNAC or Biopsy and subjected to appropriate treatment such as resection of lesions or

Radiofrequency ablation or Chemoembolisation /palliative chemotherapy whichever is feasible.(2)

\begin{tabular}{|c|c|c|c|}
\hline & $\begin{array}{l}\text { Echogenicity } \\
\text { (Hypo) or } \\
\text { Presence of } \\
\text { Extension of } \\
\text { Lesion }\end{array}$ & $\begin{array}{l}\text { Echogenicity } \\
\text { (Hypo) and } \\
\text { Presence of } \\
\text { Extension of } \\
\text { Lesion }\end{array}$ & $\begin{array}{l}\text { CECT } \\
\text { Finding }\end{array}$ \\
\hline Sensitivity & 100.0 & 48.4 & 97.5 \\
\hline Specificity & 16.7 & 100.0 & 83.3 \\
\hline False Negative & 0.0 & 51.6 & 2.5 \\
\hline False positive & 83.3 & 0.0 & 16.7 \\
\hline Positive Predictive Value & 86.1 & 100.0 & 97.5 \\
\hline Negative Predictive Value & 100.0 & 27.3 & 83.3 \\
\hline Positive Likelihood Ratio & 1.2 & - & 5.9 \\
\hline Negative Likelihood Ratio & 0.0 & 0.5 & 0.0 \\
\hline Accuracy & 86.5 & 56.8 & 95.7 \\
\hline Карра & $0.251^{*}$ & $0.233^{*}$ & $0.808^{* *}$ \\
\hline \multicolumn{4}{|c|}{$\begin{array}{c}\text { Table 1. USG and CECT \& NECT Findings in Detecting Malignancy } \\
\text { When Liver Biopsy is Gold Standard }\end{array}$} \\
\hline \multicolumn{4}{|c|}{$\begin{array}{l}* \text { - Significant at } 0.05 \text { level } * * \text { : Significant at } 0.01 \text { level Kappa }(<0 \text { : Poor } \\
\text { Agreement, } 0.0-0.2: \text { Slight agreement, } 0.2-0.4: \text { Fair agreement, } 0.4-0.6 \text { : } \\
\text { Moderate Agreement, } 0.6-0.8: \text { Substantial agreement, } 0.8-1.0 \text { : Almost perfect } \\
\text { agreement) }\end{array}$} \\
\hline
\end{tabular}

\section{Illustrations}
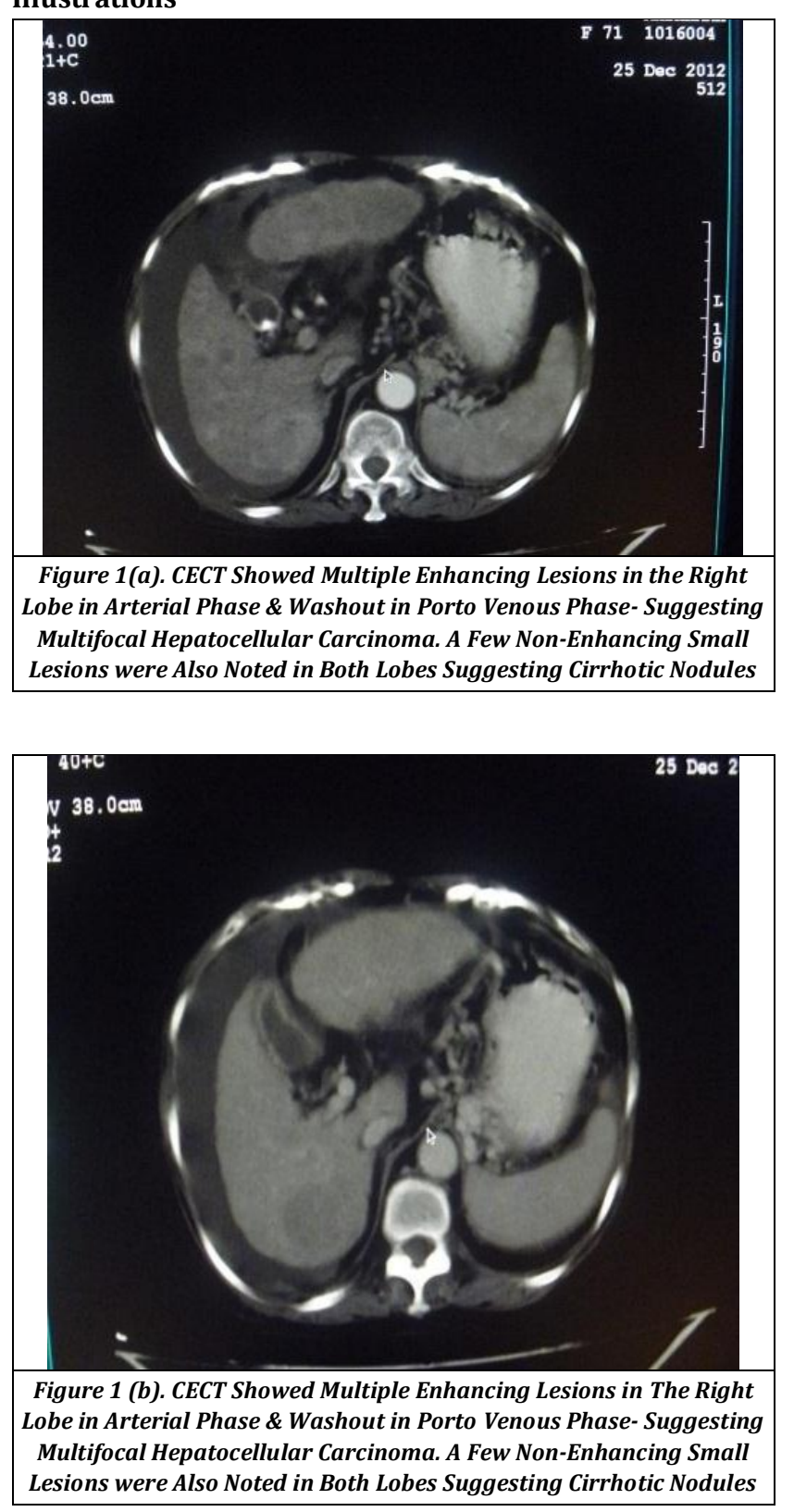

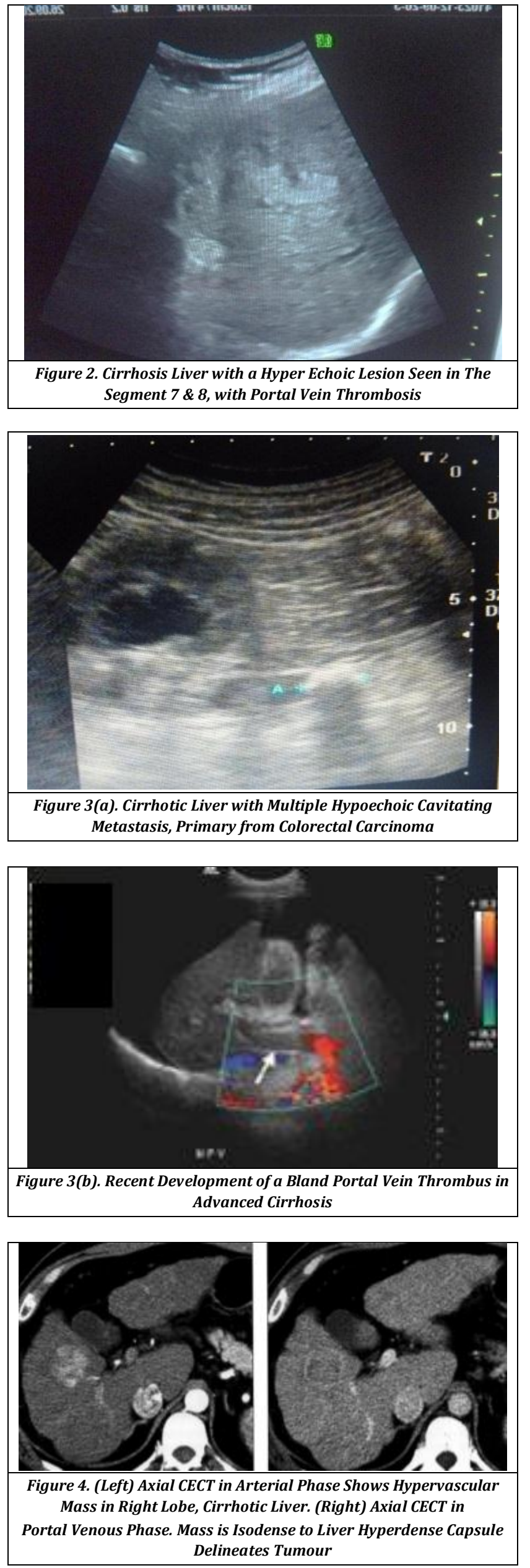

Ethical Consideration

Written informed consent was taken from all patients.

\section{Review of Literature}

Cirrhosis is present in up to $90 \%$ of patients with hepatocellular carcinoma (HCC). Common causes of cirrhosis include (a) Viral causes (b) alcohol consumption and (c) other causes like cryptogenic non-alcoholic fatty liver disease and non-alcoholic steatohepatitis. Non-alcoholic steatohepatitis is considered to be an advanced stage of non-alcoholic fatty liver disease. (4) Hepatocellular carcinoma (HCC) is the fifth most frequent cancer in the world and the third most common cause of cancer mortality.

\section{Pathogenesis of Hepatoma}

The carcinogenesis in liver cirrhosis is morphologically associated with the presence of distinct nodular lesions in the liver.(5,6) These hepatocellular nodules are well differentiated and characterised in MRI imaging include hyperplastic lesions such as large regenerative nodules (LRNs) and neoplastic lesions such as low-grade dysplastic nodules (LGDNs) and high-grade dysplastic nodules (HGDNs).(7) A low-grade dysplastic nodule is characterized by preserved hepatic architecture and low grade cytological atypia. Portal areas are present and sometimes an increase in the number of unpaired arterioles can be detected.(7) An HGDN is a neoplastic lesion with incipient malignancy. A number of architectural abnormalities can be documented, and portal areas may be present or absent in the nodule. An increased number of unpaired arteries is usually detectable. ${ }^{(8)}$

\section{Imaging Modalities}

i). Ultrasonography

Real-time sonography, in combination with colour flow Doppler sonography, is currently the most frequently used diagnostic imaging modality worldwide in the screening and evaluation of patients with cirrhosis. $(9,10)$ (Figure $3 \mathrm{~b}$ ).

Doppler evaluation in a patient with cirrhosis can demonstrate high-velocity blood flow in the enlarged hepatic artery, which becomes tortuous as fibrosis increases in cirrhosis.(Figure 2)

ii). Computed Tomography

The development of multi detector row helical computed tomography (MDCT), with its superior spatial and temporal resolution, has improved detection and characterization of focal liver lesions.(11) With single-slice helical CT, a 'dualphase' technique is commonly employed with image acquisition in the hepatic arterial and in the portal venous dominant phase. The 'triple-phase' technique includes an early arterial phase, imaged 18-25s following contrast administration Hyper vascular liver lesions are best appreciated in the late arterial phase as they show maximal enhancement relative to the background liver parenchyma. In the porto-venous phase there is maximal parenchymal enhancement with opacification of the hepatic veins. In contrast LRN and DN usually fail to exhibit this feature and appear iso-attenuating or hypo-attenuating to surrounding liver parenchyma.(12) Tumour capsule appears as a peripheral rim, which is hypoattenuating on unenhanced and arterialphase images and hyperattenuating on delayed phase images.(13) Neoplastic thrombi, however, may enhance in the arterial phase, like the main tumour.(14) (Figure 4) 


\section{Characteristic Form of HCC}

On CT scanning, hyper attenuation in the arterial phase occurs in a variable case and it is characteristic enough to permit the diagnosis. The characterization of liver nodules is challenging when the findings are not "typical" of HCC, and the Liver Imaging Reporting and Data (LI-RAD) classification system has recently been introduced to improve consistency and aid in management decisions.

Echogenic liver metastases (Fig-3a), tumours of gastrointestinal origin, as well as more vascular tumours, are more likely to develop this can also be seen with primary HCC. Haemangioma is the most common benign tumour of the liver. The pathognomonic diagnostic findings for haemangioma are as follows: on unenhanced CT, hypodensity similar to that of vessels; on dynamic contrast-enhanced CT imaging, peripheral nodular enhancement and a centripetal fill-in pattern with the attenuation of enhancing areas identical to that of the aorta and blood pool.(15) With progressive cirrhosis, haemangiomas are likely to decrease in size and become more fibrotic and difficult to diagnose radiologically and pathologically. $(15,16)$ Simple hepatic cysts are benign developmental lesions that do not communicate with the biliary tree.(17) The current theory regarding the origin of true hepatic cysts is that they originate from hamartomatous tissue(17),(18). They are more often discovered in women and are almost always asymptomatic. A hepatic cyst appears as a homogeneous and hypoattenuating lesion on unenhanced CT scans, with no enhancement of its wall or content after intravenous administration of contrast material. It is typically round or ovoid and well-defined.(18)

\section{RESULTS}

121 patients were included in the study, of which $80 \%$ were males. Maximum number of patients with cirrhosis belonged to the $60-69$ age group. $71.1 \%$ of patients were having aetiology of alcohol related Chronic liver disease. $6.6 \%$ of patients were chronic HBV related \&4.1\% were HCV related chronic liver disease. $72.7 \%$ of patients had atrophied right lobe. $17.4 \%$ of patients had enlarged left lobe. $63.6 \%$ of patients had main portal vein size of more than $12,11.6 \%$ of patient had thrombus in portal vein. $35.5 \%$ of patients were treated with sorafenib, $9.9 \%$ of patients were treated with chemotherapy, $4 \%$ of patients were taken radiofrequency ablation. Remaining $67.8 \%$ of patients had taken other supportive treatment.

\section{DISCUSSION}

Among 121 patients included in the study, there were male preponderance. Maximum number of patients with chronic liver disease belonged to 60-69 years of age group. Commonest aetiology of chronic liver disease was alcohol consumption \& which was 71\%. Majority of alcohol consumption among our study population was between 10-20 years. Ultrasonography of abdomen revealed the following characteristics' in our study: $92 \%$ of cases showed reduced liver size $\$ 72 \%$ of cases had atrophied right lobe, $100 \%$ of cases had nodular liver surface \& coarse echotexture highly suggestive of cirrhosis pattern. $63 \%$ of cases had enlarged main portal vein with $12 \%$ had presence of thrombus within. These sonographic characteristics were pathognomonic of chronic liver disease. $31 \%$ of cases had focal lesions in liver. No lesions were detected in $69 \%$ of cases by ultrasonography Focal lesions were detected predominantly in the right lobe.
Rich vascularity was detected in $34 \%$ of cases\& extension of lesion to adjacent structures in $40 \%$ cases. Among $40 \%$ of cases, $100 \%$ of cases had extension to portal vein. These sonographic features were suspicious for malignancy. In our study, CECT Abdomen revealed the following characteristics: $20 \%$ of cases had single lesion, $9 \%$ had 2 lesions, $10 \%$ had multiple lesions. No lesions were detected in $61 \%$ of cases. Right lobe predilection of focal lesions was 55\% \& 34\% of cases had both lobe involvement. Focal lesions with regular margins were $60 \%$, while irregular margins were $40 \%$. $98 \%$ of focal lesions were hypoechoic \& $53 \%$ had extension to adjacent structures. Among $53 \%$ of cases $100 \%$ extension to portal vein $\& 16 \%$ extension to inferior vena cava. Among the focal lesions, $85 \%$ had contrast enhancement.

Focal lesions showed $100 \%$ contrast enhancement in arterial phase $\& 95 \%$ showed washout or hypodense in portal venous phase suggestive of primary malignancy hepatocellular carcinoma. Those lesions appear hyperdense in arterial phase \& portal venous phase were $5 \%$ suggestive of secondaries-hepatic metastasis. According to CECT, $81 \%$ of cases had primary malignancy, while $41 \%$ of cases had secondaries \& $15 \%$ had benign lesions. According to liver biopsy, which was taken as our gold standard investigation, $87 \%$ were malignant \& $13 \%$ were benign lesions.

$35 \%$ of cases were diagnosed as chronic liver disease with portal hypertension, $26 \%$ of cases were diagnosed as only chronic liver disease, $13 \%$ of cases were diagnosed as hepatocellular carcinoma $\& 17 \%$ cases were hepatocellular carcinoma with portal vein thrombosis. $4 \%$ cases were chronic liver disease with regenerating nodules, while $2.5 \%$ of cases were hepatic metastasis from colorectal \& pancreatic primary carcinomas.

$36 \%$ of cases were treated with sorafenib, $10 \%$ cases with TACE \& 4\% with RFA. Among 121 patients 50\% were having stable disease while $31 \%$ of cases were expired.

The sensitivity of ultrasonography in detecting malignancy as hypoechogenecity of lesions or extension of lesion to adjacent structures was $100 \%$ \& those with both hypoechogenecity of lesions and extension of lesion to adjacent structures was only $48.4 \%$. The sensitivity of CECT in detecting malignancy was $97.5 \%$. The specificity of ultrasonography in detecting malignancy as hypoechogenecity of lesions or extension of lesion to adjacent structures was $16.7 \%$ \& those with both hypoechogenecity of lesions and extension of lesion to adjacent structures was only $100 \%$. The specificity of CECT in detecting malignancy was $83.3 \%$. The positive predictive value of ultrasonography in detecting malignancy as hypoechogenecity of lesions or extension of lesion to adjacent structures was $86.1 \%$ \& those with both hypoechogenecity of lesions and extension of lesion to adjacent structures was only $100 \%$. The positive predictive value of CECT in detecting malignancy was $97.5 \%$.

\section{CONCLUSIONS}

Maximum number of patients with chronic liver disease belonged to 60-69 years of age group. The age of the patient in the study showed significant association with the outcome. The sensitivity of ultrasonography in detecting malignancy as hypoechogenecity of lesions or extension of lesion to adjacent structures was $100 \%$ \& those with both hypoechogenecity of lesions and extension of lesion to adjacent structures was only $48.4 \%$. The sensitivity of CECT in detecting malignancy was 
97.5\%. The specificity of ultrasonography in detecting malignancy as hypoechogenecity of lesions or extension of lesion to adjacent structures was $16.7 \%$ \& those with both hypoechogenecity of lesions and extension of lesion to adjacent structures was only $100 \%$. The specificity of CECT in detecting malignancy was $83.3 \%$. Hence, ultrasound is a screening diagnostic modality \& CECT is an accurate diagnostic tool for evaluating benign from malignant focal lesions in liver and invasive modalities like liver biopsy could be prevented by proper \& planned dynamic contrast study of abdomen.

\section{REFERENCES}

[1] Bruix J, Sherman M, Practice Guidelines Committee, et al. Management of hepatocellular carcinoma. Hepatology 2005;42(5):1208-36.

[2] Hussain SM. Liver MRI: correlation with other imaging modalities and histopathology. Berlin, Germany: Springer-Verlag 2007.

[3] Livraghi T. Percutaneous ethanol injection in the treatment of hepatocellular carcinoma in cirrhosis. Hepatogastroenterology 2001;48(37):20-4.

[4] Hussain SM, Reinhold C, Mitchell DG. Cirrhosis and lesion characterization at MR imaging. Radiographics 2009;29(6):1637-52. radiographics.rsna.org,

[5] Borzio M, Roncalli M, Trere D, et al. Preneoplastic cellular changes in liver. Hepatology 1998;28(5):1435.

[6] Ariff B, Lloyd CR, Khan S, et al. Imaging of liver cancer. World J Gastroenterol 2009;15(11):1289-300. wjg@wjgnet.com

[7] International Working Party. Terminology of nodular hepatocellular lesions. Hepatology 1995;22(3):983-93.

[8] Roncalli M, Roz E, Coggi G, et al. The vascular profile of regenerative and dysplastic nodules of the cirrhotic liver: implications for diagnosis and classification. Hepatology 1999;30(5):1174-8.
[9] Schneider AW, Kalk JF, Klein CP. Hepatic arterial pulsatility index in cirrhosis: correlation with portal pressure. J Hepatol 1999;30(5):876-81.

[10] Zimmerman P, Farooki S, Lu DSK, et al. Doppler sonography of the hepatic vasculature. Appl Radiol 2000;29:11-18.

[11] Foley WD, Mallisee TA, Hohenwalter MD, et al. Multiphase hepatic CT with a multirow detector CT scanner. AJR Am J Roentgenol 2000;175(3):679-85.

[12] Baron RL, Brancatelli G. Computed tomographic imaging of hepatocellular carcinoma. Gastroenterology 2004;127(5 Suppl 1):S133-S43.

[13] Bartolozzi C, Crocetti L, Pina DMC. How to differentiate liver lesions in cirrhosis. JBR-BTR 2007;90(6):475-81.

[14] Ishak KG, Goodman ZD, Stocker JT. Atlas of tumour pathology: tumours of the liver and intrahepaticbile ducts. 3rd series, fascicle 31. Washington, DC: Armed Forces Institute of Pathology, 1999.

[15] Jang HJ, Kim TK, Lim HK, et al. Hepatic hemangioma: atypical appearances on CT, MR imaging and sonography. American Journal of Roentgenology 2003;180(1):135-41.

[16] Brancatelli G, Federle MP, Blachar A, et al. Hemangioma in the cirrhotic liver: diagnosis and natural history. Radiology 2001;219(1):69-74.

[17] Van Sonnenberg E, Wroblicka JT, D'Agostino HB, et al. Symptomatic hepatic cysts: percutaneous drainage and sclerosis. Radiology 1994;190(2):387-92.

[18] Mathieu D, Vilgrain V, Mahfouz AE, et al. Benign liver tumours. Magn Reson Imaging Clin $\mathrm{N}$ Am 1997;5(2):255-88. 